\title{
Solidification of Immiscible Alloys Under the Effect of Electric and Magnetic Fields
}

\author{
Hong-Xiang Jiang ${ }^{1} \cdot$ Jiu-Zhou Zhao ${ }^{1}$ \\ Received: 3 January 2018/Revised: 6 February 2018/Published online: 20 April 2018 \\ (C) The Chinese Society for Metals and Springer-Verlag GmbH Germany, part of Springer Nature 2018
}

\begin{abstract}
Immiscible alloys have aroused considerable interests in the last decades on account of their special physical and mechanical properties and potential applications. A considerable number of researches have been implemented to investigate the solidification behaviors of immiscible alloys in electric and magnetic fields. It has been indicated that the magnetic field and electric current can remarkably affect the solidification process and microstructures of immiscible alloys. The solidification techniques under the effects of electric and magnetic fields have great potentials for the fabrication of immiscible alloys. This paper reviews the research work in this field in recent years.
\end{abstract}

Keywords Immiscible alloys · Solidification · Microstructure evolution · Electric current · Magnetic field · Electric-magnetic fields

\section{Introduction}

Immiscible alloys with a miscibility gap in the liquid state are a broad kind of materials. Some of them have tremendous potential applications in the fields such as chemical, automobile, machinery, electronic industry because of their good physical and mechanical properties; for example, $\mathrm{Cu}-\mathrm{Pb}, \mathrm{Al}-\mathrm{Pb}$ or $\mathrm{Al}-\mathrm{Bi}$ alloys are attractive candidate materials for advanced bearings in automotive applications if the soft $\mathrm{Pb}$ or $\mathrm{Bi}$ phase is dispersed in a hard matrix like $\mathrm{Al}$ or $\mathrm{Cu}$ [1-5]. However, these alloys have an essential drawback in that the miscibility gap poses problems during solidification. When a single-phase liquid is cooled into the miscibility gap, the components are no longer miscible and two liquid phases develop [2, 5]. Generally, the liquid-liquid decomposition begins with the nucleation of the minority phase droplets. These droplets grow and coarsen then. They may also sink or float as a result of the density difference between phases under the effect of gravity (Stokes sedimentation) and migrate due to

Available online at http://link.springer.com/journal/40195

Jiu-Zhou Zhao

jzzhao@imr.ac.cn

1 Institute of Metal Research, Chinese Academy of Sciences, Shenyang 110016, China the temperature gradient or concentration gradient (Marangoni motion). The migrations of the droplets lead to the formation of a microstructure with great phase segregation [5-8]. In recent decades, extensive efforts have been made to investigate the solidification process of immiscible alloys [9-13]. The results demonstrated that magnetic field and electric current have great effect on the microstructure evolution. This paper will review the research work and progress in this field during the last several decades.

\section{Solidification of Immiscible Alloys in a Magnetic Field}

\subsection{Solidification of Immiscible Alloys in a Low- Strength Magnetic Field}

Yang et al. [14] carried out the directional solidification experiment with $\mathrm{Al}-6.5 \mathrm{wt} \% \mathrm{Bi}$ alloy in a $0.2 \mathrm{~T}$ transverse static magnetic field. They found that the microstructure of the alloy was characterized by aligned $\mathrm{Bi}$ fibers or $\mathrm{Bi}$ droplets. The spacing between the Bi fibers as well as the diameter of Bi droplets decreased in a transverse magnetic field. He and Zhao et al. $[15,16]$ studied the influence of a magnetic field of the strength lower than $1 \mathrm{~T}$ on the solidification of Al-Bi alloys. The results demonstrated that the imposition of a magnetic field damps the melt convection and lowers down the moving velocity of the Bi- 
rich droplets. The increase in the magnetic field strength can lead to the decrease in the average size of the Bi-rich particles. They also found that the application of the static magnetic field may benefit the coupled growth in the Al-Bi immiscible system. A structure with aligned Bi fibers even form in the hypermonotectic alloys solidified in a static magnetic field, as shown in Fig. 1.

In order to understand the detailed effects of a static magnetic field on the solidification of immiscible alloys, Zhao et al. $[17,18]$ carried out a series of continuous solidification experiments with $\mathrm{Al}-\mathrm{Pb}$ alloys by using a Bridgman-type solidification setup with a static magnetic field device (as shown schematically in Fig. 2) and did systematic modeling and simulation in connection with the experiments. The results show that a low-strength static magnetic field only leads to an insignificant decrease in the Marangoni migration velocity as well as in the Stokes settlement velocity of the minority phase droplets (MPDs) during the liquid-liquid decomposition (see Fig. 3) and thus does not affect the solidification process through changing the Marangoni and Stokes moving velocities of the MPDs. It mainly affects the solidification of immiscible alloy through an efficient suppression of the melt convection (see Figs. 4, 5). The application of static magnetic field results in a more homogenous distribution of the nucleation rate of the MPDs along radial direction of the sample (see Fig. 6). It also leads to a decrease in the size of the maximum droplet and prevents the accumulation of the droplets in front of the solidification interface. All of them are favorable for the formation of an immiscible alloy with finely dispersed microstructure.

\subsection{Solidification of Immiscible Alloys in a High- Strength Magnetic Field}

Yasuda et al. [19] investigated the influence of a $10 \mathrm{~T}$ static magnetic field on the microstructure formation of the Al-In

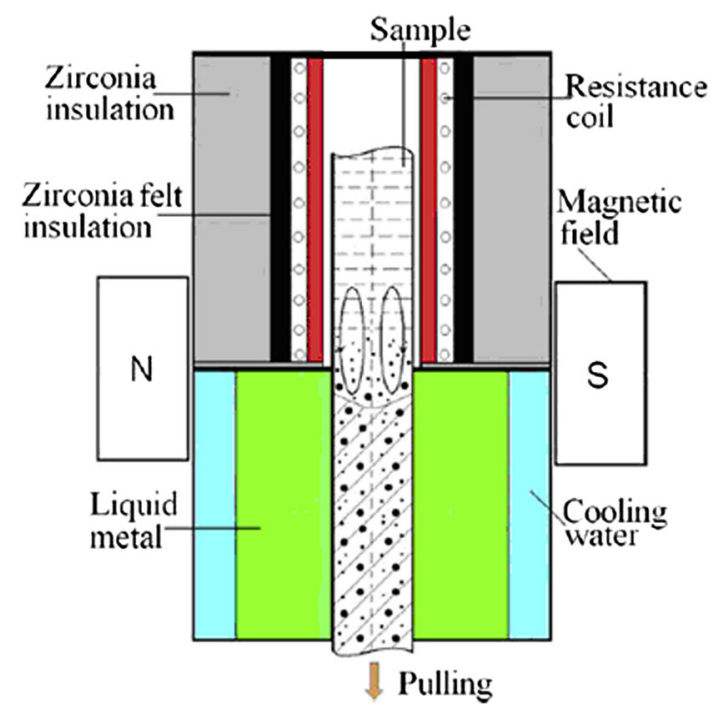

Fig. 2 Schematic diagram of the continuous solidification facility of an immiscible alloy in a transverse static magnetic field [17]

alloys. Their results demonstrated that the magnetic field reduces the convective flow of melt and enhances the engulfment of the In-rich droplets by the Al matrix and thus promotes the coupled growth and the formation of an aligned In-rich fiber structure in the Al-10 at.\%In alloys, as shown in Fig. 7. Zhang et al. [20] carried out the solidification experiments with an electromagnetically levitated $\mathrm{Cu}-\mathrm{Co}$ drop and explored the effect of a $2 \mathrm{~T}$ static magnetic field on the structures. They found that, in contrast to a bimodal $\mathrm{Cu}$-rich minority particle size distribution shown by the specimen solidified under the zero magnetic field, the specimen solidified in magnetic fields shows a singular size distribution for the minor $\mathrm{Cu}$-rich phase in a Co-rich matrix, as shown in Fig. 8. Yasuda et al. [21], Zhang et al.
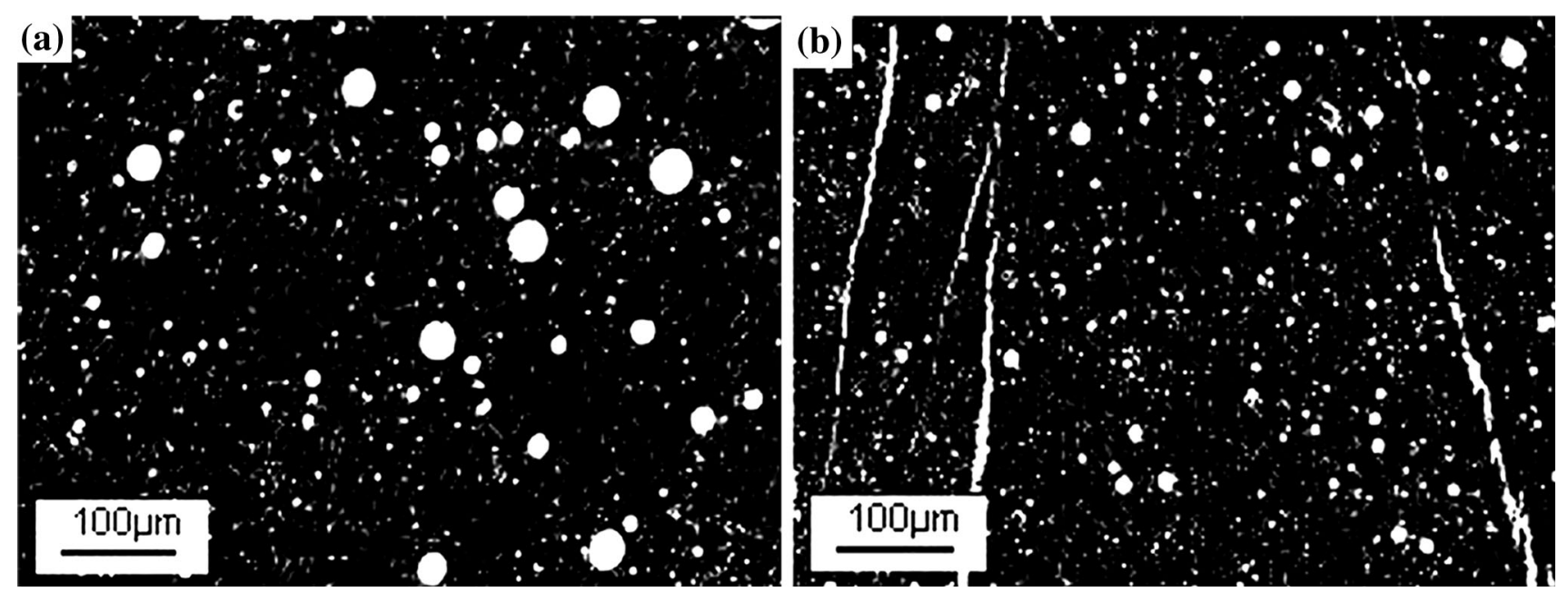

Fig. 1 Microstructures of the Al-12 wt\% Bi alloys solidified at the rate of $5 \mathrm{~mm} / \mathrm{s}$ under the magnetic field intensities of a $0 \mathrm{~T}$, $\mathbf{b} 1 \mathrm{~T}$ [16] 


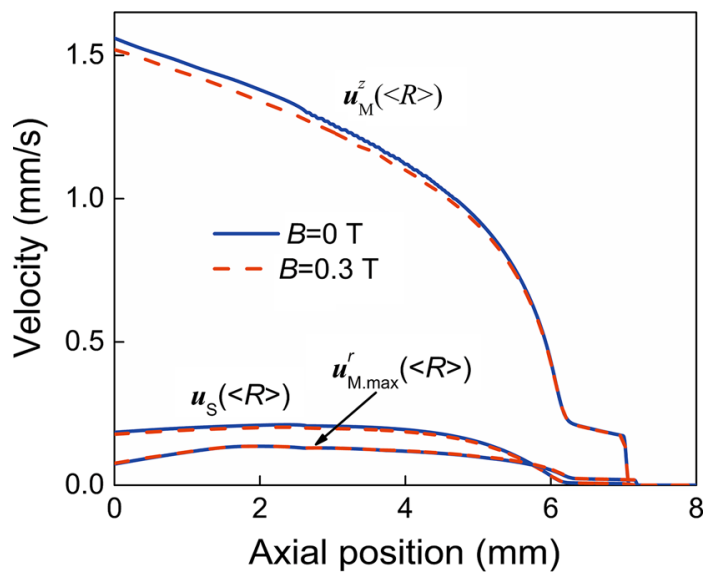

Fig. 3 Motion velocities of the average size droplets in front of the solidification interface along the central $z$-axes (axial position) for the Al-5 wt $\% \mathrm{~Pb}$ alloy continuously solidified at the rate of $5 \mathrm{~mm} / \mathrm{s} . B$ is the magnetic strength, $\mathbf{u}_{\mathrm{M}}^{Z}(\langle R\rangle), \mathbf{u}_{\mathrm{S}}(\langle R\rangle)$ and $\mathbf{u}_{\mathrm{M} \cdot \max }^{r}(\langle R\rangle)$ are the $z$ vector of the Marangoni velocity, the Stokes velocity and the maximums of the $r$-component (radial position) of the Marangoni velocity of the droplets with average size, respectively [17]

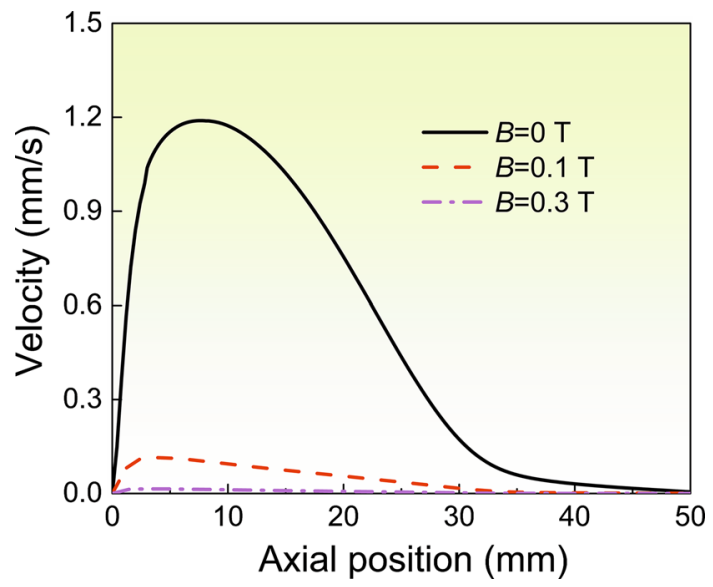

Fig. 4 Convective flow velocities of the melt along the central $z$ axes for the Al-5 wt $\% \mathrm{~Pb}$ samples continuously solidified at the rate of $5 \mathrm{~mm} / \mathrm{s}$ in magnetic fields of different strengths [17]

[22] and Zheng et al. [23] performed a lot of solidification experiments with $\mathrm{Cu}-\mathrm{Pb}$ and $\mathrm{Bi}-\mathrm{Zn}$ immiscible alloys under the effect of the magnetic field of the strength above $1 \mathrm{~T}$. They found that the magnetic field can reduce the motion velocity and the coalescence rate of the MPDs which leads to a reduction in the phase macro-segregation and promote the formation of a well-dispersed microstructure.

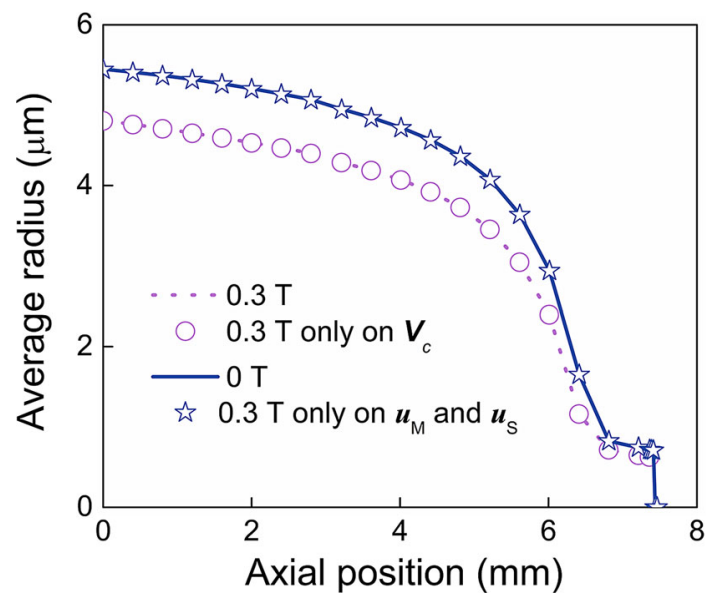

Fig. 5 Average radius of the MPDs in front of the solidification interface along the central $z$ axes for the $\mathrm{Al}-5 \mathrm{wt} \% \mathrm{~Pb}$ alloy sample continuously solidified at the rate of $5 \mathrm{~mm} / \mathrm{s}$. The insignificant difference between the solid line and the stars indicates that the applied magnetic field does not affect the solidification process through changing the Marangoni and Stokes moving velocities of the MPDs. The coincidence between the dotted line and the circles demonstrates that the magnetic field affects the solidification process and microstructure mainly through restraining the convective flow of the melt. $\mathbf{V}_{\mathrm{C}}, \mathbf{u}_{\mathrm{S}}$ and $\mathbf{u}_{\mathrm{M}}$ are the convective velocity of the matrix liquid, the Stokes motion and Marangoni migration velocities of the droplet, respectively [17]

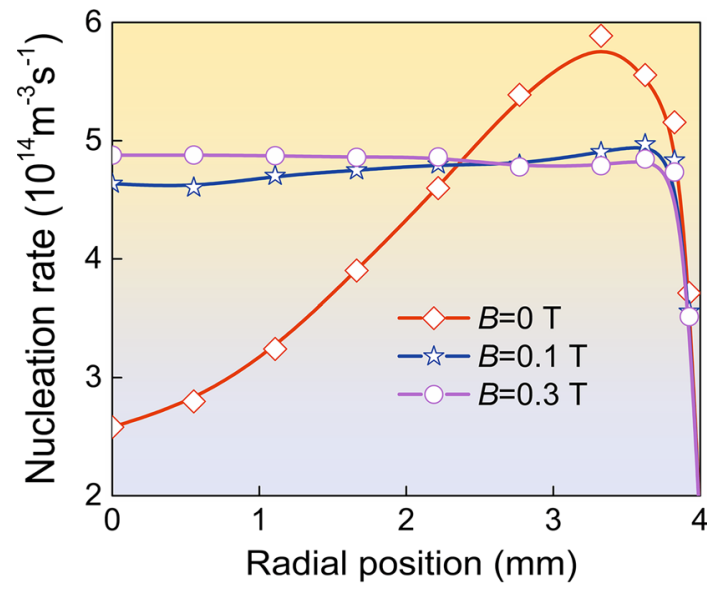

Fig. 6 Maximum nucleation rates of the MPDs along the radial direction for the $\mathrm{Al}-5 \mathrm{wt} \% \mathrm{~Pb}$ samples continuously solidified at the rate of $5 \mathrm{~mm} / \mathrm{s}$ under the effect of static magnetic fields [17]

\section{Solidification of Immiscible Alloys Under the Effect of Electric Current}

\subsection{Solidification of Immiscible Alloys Under the Effect of Direct Current}

Zhao and Jiang et al. [3, 24-27] explored the effect of a direct current (DC) on the solidification behavior of $\mathrm{Al}-\mathrm{Pb}$ 

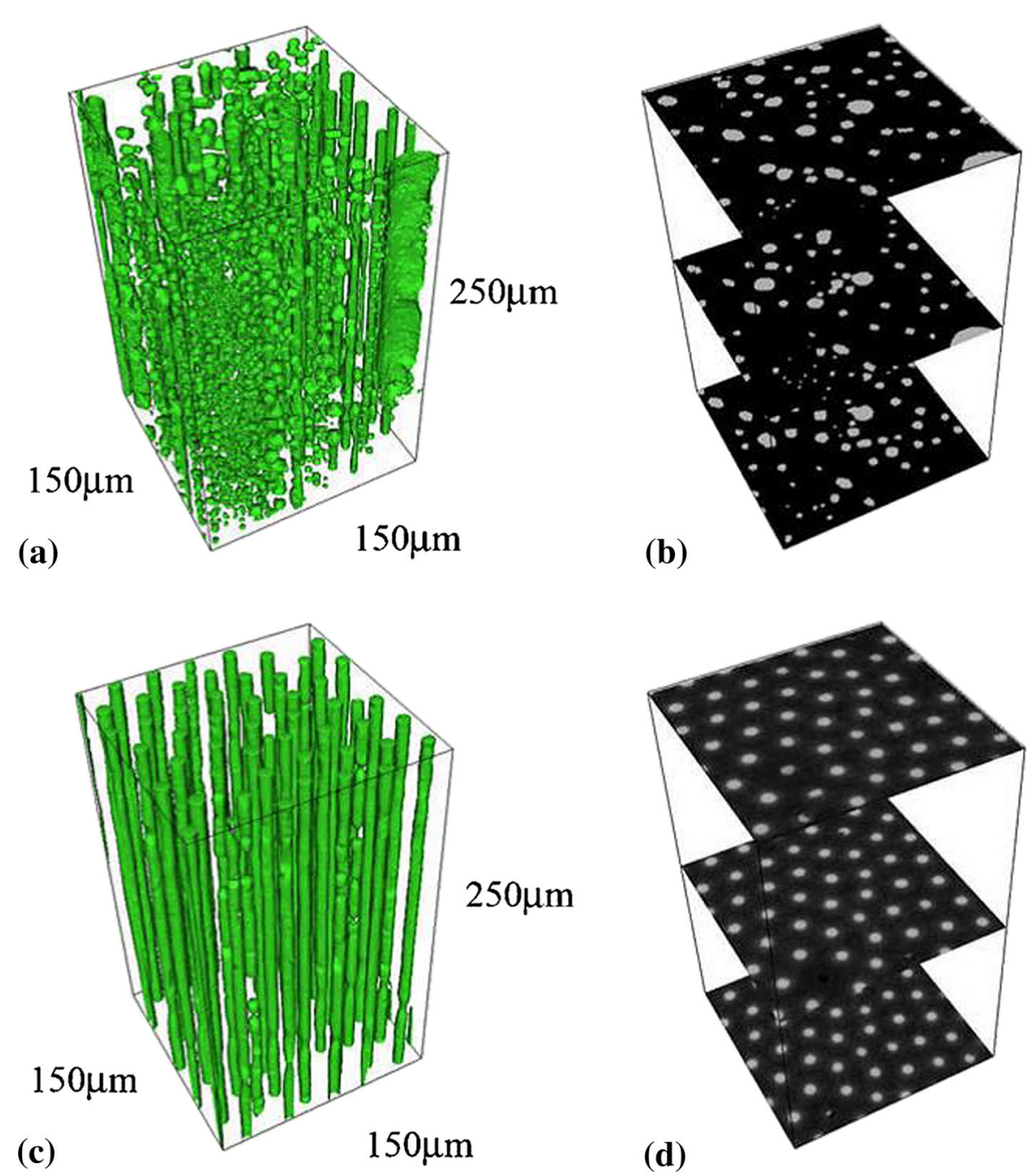

Fig. 7 Micro-X-ray tomography images of the Al-10 at.\%In alloys directionally solidified at the rate of $2.7 \mu \mathrm{m} / \mathrm{s}$ under the effect of a magnetic field: a 3D image of the In-rich phase in a specimen solidified without a magnetic field; $\mathbf{b}$ the slice images of $\mathbf{a}$; $\mathbf{c} 3 \mathrm{D}$ image of a specimen solidified in a $10 \mathrm{~T}$ magnetic field; $\mathbf{d}$ the slice images of $\mathbf{c}$ [19]

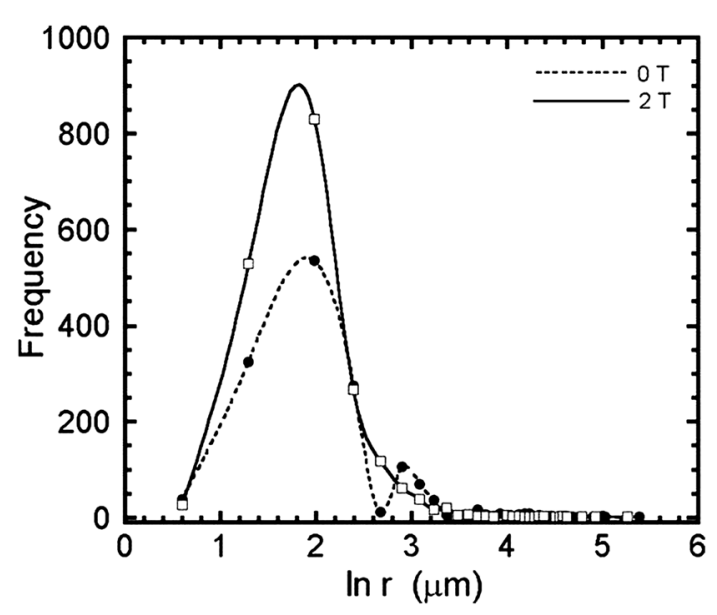

Fig. 8 Comparison of droplet size distribution in the electromagnetically levitated $\mathrm{Cu}_{50}-\mathrm{Co}_{50}$ alloy samples solidified in magnetic fields of different strengths [20] and $\mathrm{Al}-\mathrm{Bi}$ immiscible alloys both experimentally and numerically. The results indicate that a DC affects the solidification process mainly through changing the spatial motions of the MPDs. When the electric conductivity of the minority phase droplet is higher than the electric conductivity of the matrix liquid, a direct current causes the MPDs to migrate from the surface to the center of the sample. When the electric conductivity of the minority phase droplet is lower than the electric conductivity of the matrix liquid, a direct current causes the MPDs to migrate from the center to the surface of the sample. One can control the motion of the MPDs by applying electric current of different densities and manufacture immiscible alloy wires/rods with either welldispersed microstructure or a core/shell microstructure, as shown in Figs. 9 and 10 [25, 26]. 

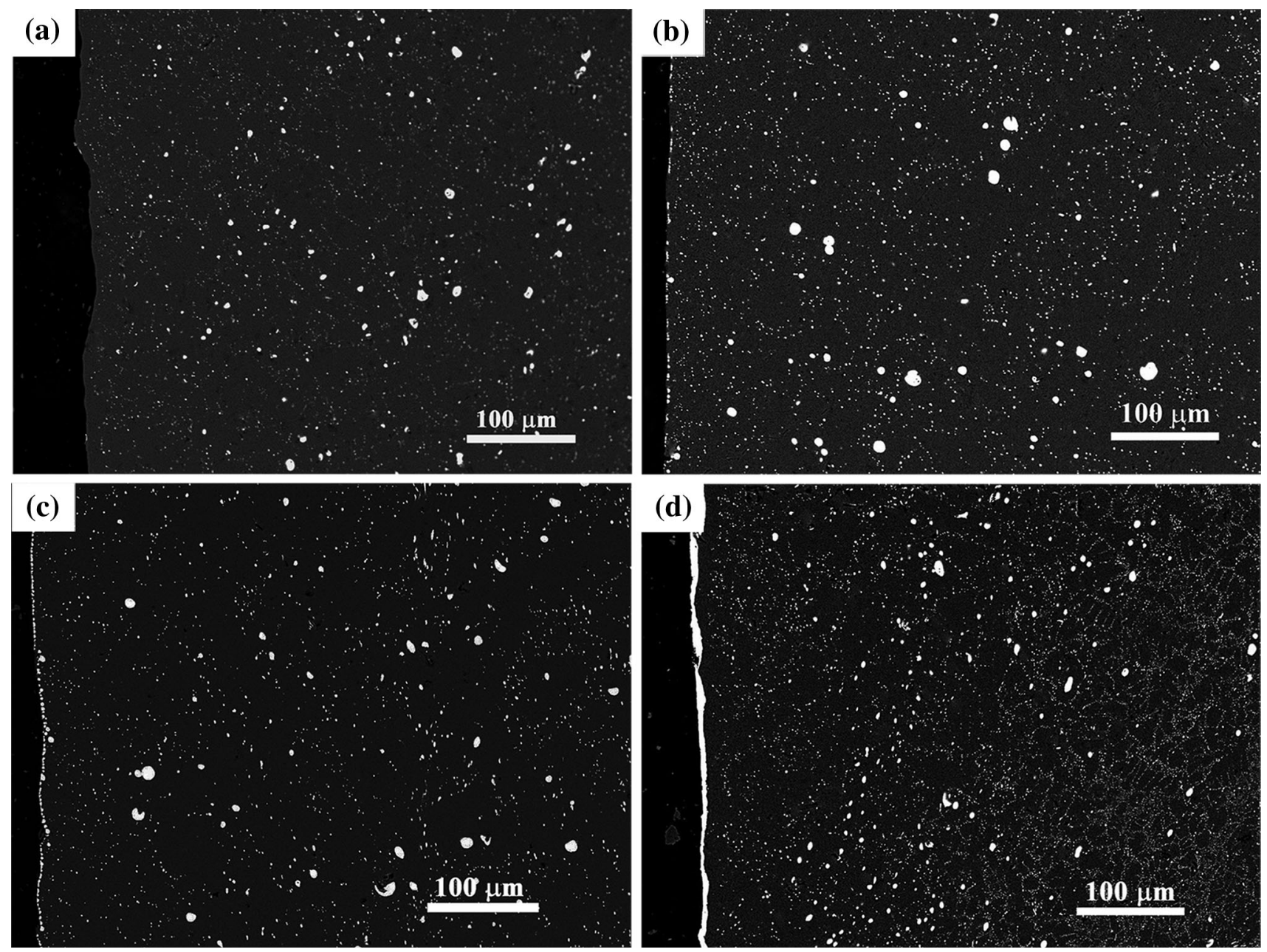

Fig. 9 Microstructures of the regions close to the surface of the $\mathrm{Al}-7 \mathrm{wt} \% \mathrm{~Pb}$ samples continuously solidified at a given rate of $8 \mathrm{~mm} / \mathrm{s}$ under the effect of different DC densities: a $0 \mathrm{~A} / \mathrm{cm}^{2}, \mathbf{b} 170 \mathrm{~A} / \mathrm{cm}^{2}, \mathbf{c} 195 \mathrm{~A} / \mathrm{cm}^{2}, \mathbf{d} 438 \mathrm{~A} / \mathrm{cm}^{2}$. There is a layer poor in the Pb-rich particles on the surface of the sample solidified without a DC. The sample solidified with a DC density of $170 \mathrm{~A} / \mathrm{cm}^{2}$ shows a microstructure with a uniform distribution of the $\mathrm{Pb}$-rich particles across the whole section of the sample. The sample shows a layer rich in the Pb-rich particles on the surface when the $\mathrm{DC}$ density is $195 \mathrm{~A} / \mathrm{cm}^{2}$. A continuous shell of Pb-rich phase forms on the surface of the sample solidified under the effect of a DC density of $438 \mathrm{~A} / \mathrm{cm}^{2}[25]$

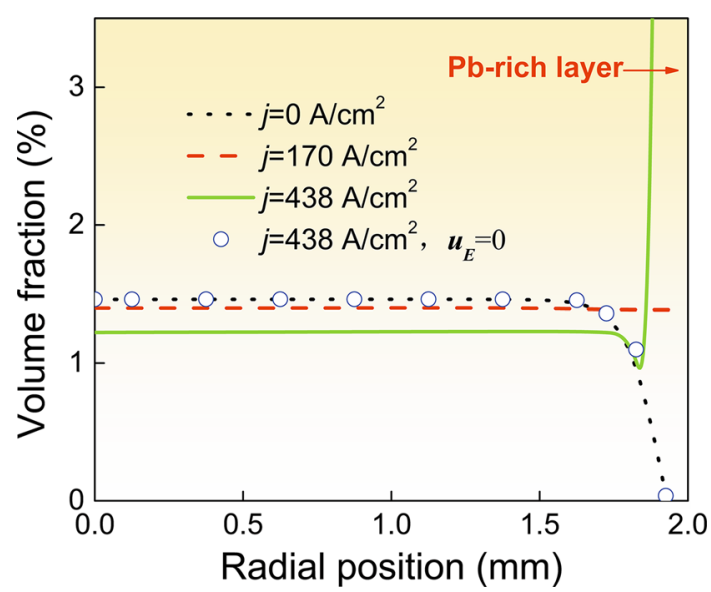

Fig. 10 Volume fraction of the MPDs along the radial direction of the Al-7 wt $\% \mathrm{~Pb}$ alloys solidified at the rate of $8 \mathrm{~mm} / \mathrm{s}$ under the effect of a direct current. $j$ is the current density. $\mathbf{u}_{E}$ is the moving velocity of the MPDs due to the electric current. The circles are the volume fraction of the minority phase calculated by assuming that at $j=438 \mathrm{~A} / \mathrm{cm}^{2}$; the DC does not affect the motions of the MPDs. The negligible differences between the circles and the dot lines demonstrate that a DC affects the phase segregation along the radial direction of the sample mainly by changing the spatial motions of the MPDs [24] 


\subsection{Solidification of Immiscible Alloys Under the Effect of Electric Current Pulse}

Zhu and Wang et al. [28, 29] investigated the effect of electric current pulse (ECPs) on the microstructure formation of Al-Bi immiscible alloys. They reported that the ECPs caused the Bi-rich droplets to move toward the surface of the sample during the liquid-liquid decomposition. Zhao et al. [3, 26, 30-32] investigated the solidification behavior of $\mathrm{Al}-\mathrm{Pb}, \mathrm{Cu}-\mathrm{Bi}-\mathrm{Sn}$ immiscible alloys under the effect of the ECPs both experimentally and numerically. The results indicate that the ECPs mainly affect the microstructure formation through changing the nucleation behaviors of the MPDs. When the electrical conductivity of the MPDs is higher than the electrical conductivity of the matrix, ECPs increase the nucleation rate and promote the formation of a well-dispersed microstructure. Otherwise, ECPs lead to a decrease in the nucleation rate and promote the formation of a phase segregated microstructure, as shown in Figs. 11, 12 and 13. The materials with a welldispersed microstructure can be prepared by solidifying immiscible alloys under the effect of ECPs when the MPDs have a higher electrical conductivity compared to the matrix phase.

\section{Solidification of Immiscible Alloys Under the Effect of the Electric-Magnetic Fields}

In the early 1990s, Zhao et al. [33, 34] investigated the effect of the orthogonal electric-magnetic field on the solidification of $\mathrm{Al}-\mathrm{Pb}$ and $\mathrm{Zn}-\mathrm{Pb}$ immiscible alloys, as
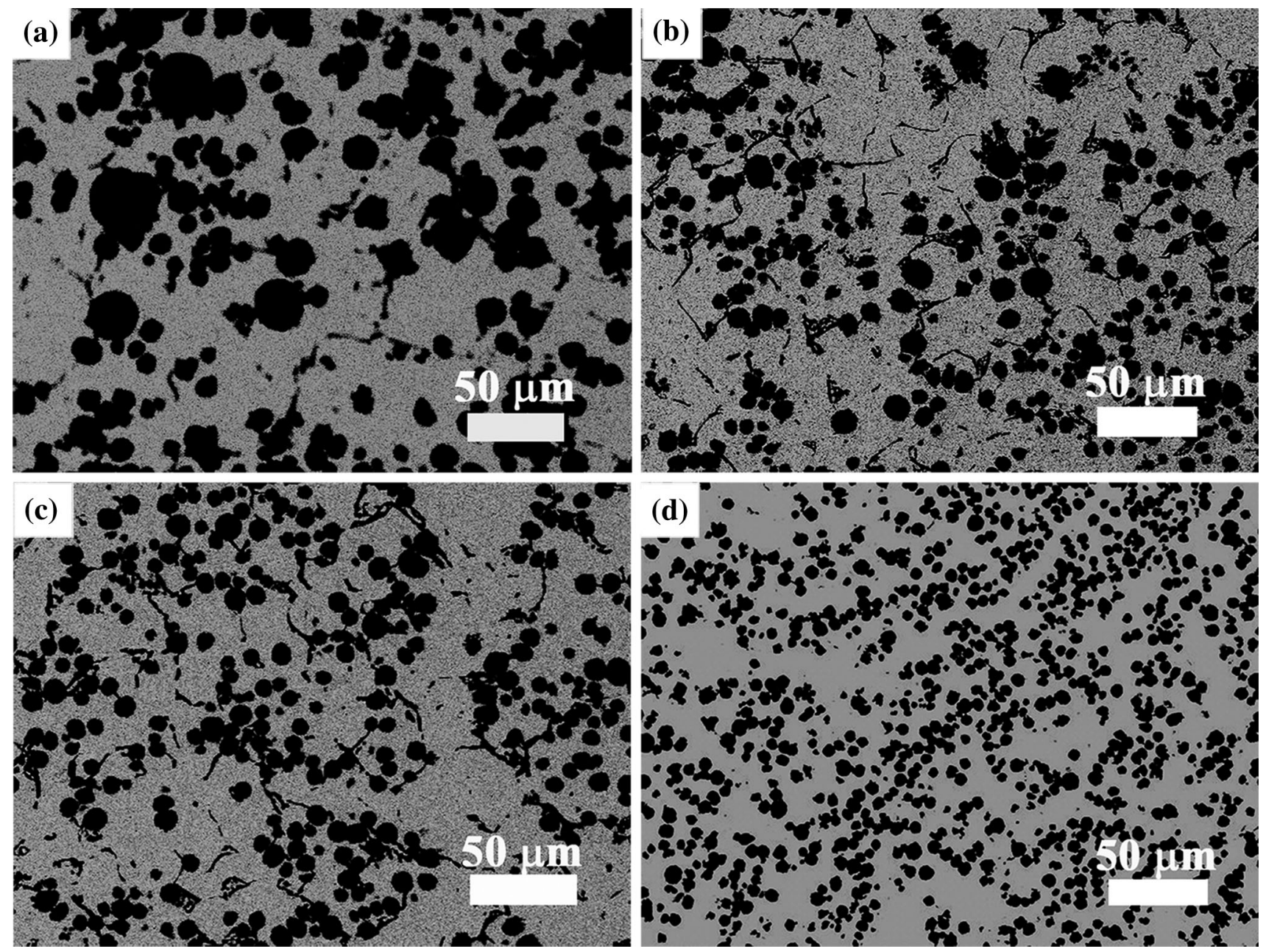

Fig. 11 Microstructures of Bi-10 wt\%Cu-10 wt\%Sn alloy solidified continuously at the rate of $10 \mathrm{~mm} / \mathrm{s}$; a without ECPs, b-d with ECPs, the frequency and duration of each ECP are $50 \mathrm{~Hz}$ and $6 \mu \mathrm{s}$, and the peak values of the pulse current density are $\mathbf{b} 1 \times 10^{8} \mathrm{~A} / \mathrm{m}^{2}, \mathbf{c} 2 \times 10^{8} \mathrm{~A} / \mathrm{m}^{2}$, d $3 \times 10^{8} \mathrm{~A} / \mathrm{m}^{2}[3]$ 

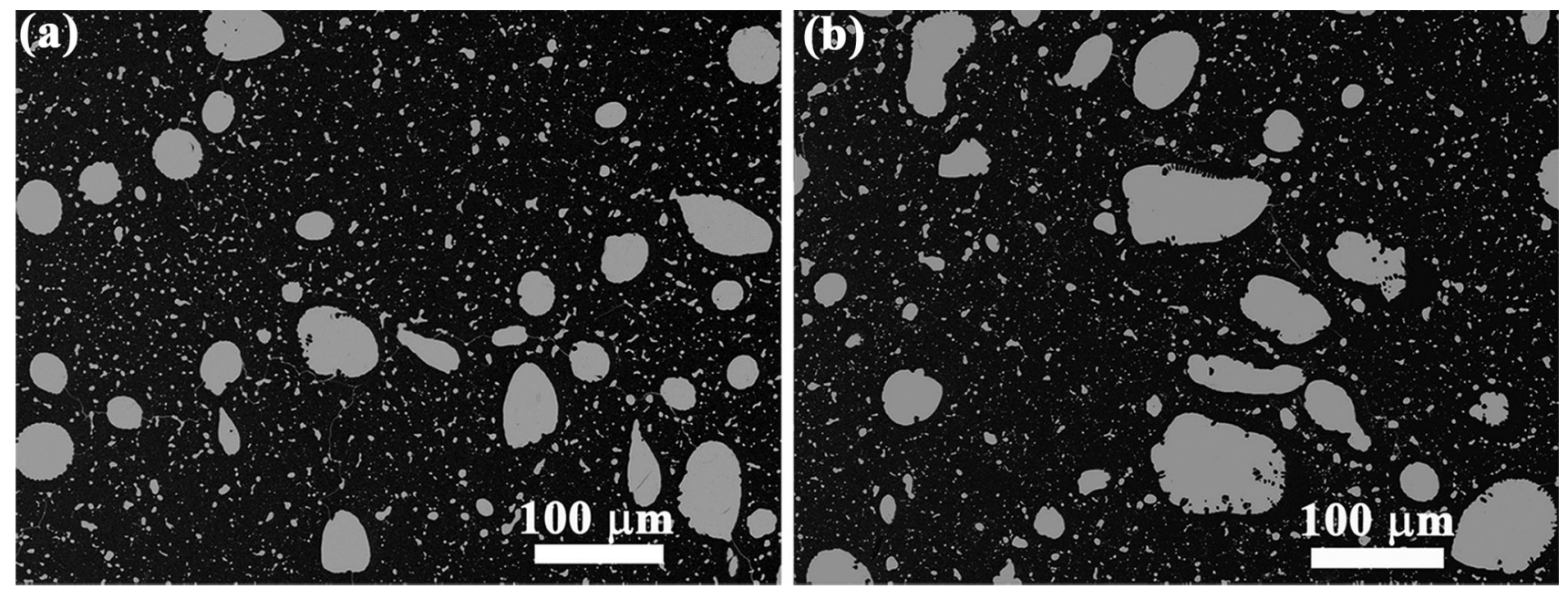

Fig. 12 Microstructures of $\mathrm{Cu}-25 \mathrm{wt} \% \mathrm{Bi}-25 \mathrm{wt} \% \mathrm{Sn}$ alloy solidified continuously at the rate of $10 \mathrm{~mm} / \mathrm{s}$; a without ECPs, b with ECPs, the frequency and duration of each ECP are $50 \mathrm{~Hz}$ and $6 \mu \mathrm{s}$, and the peak value of the pulse current density is $3 \times 10^{8} \mathrm{~A} / \mathrm{m}^{2}[31]$
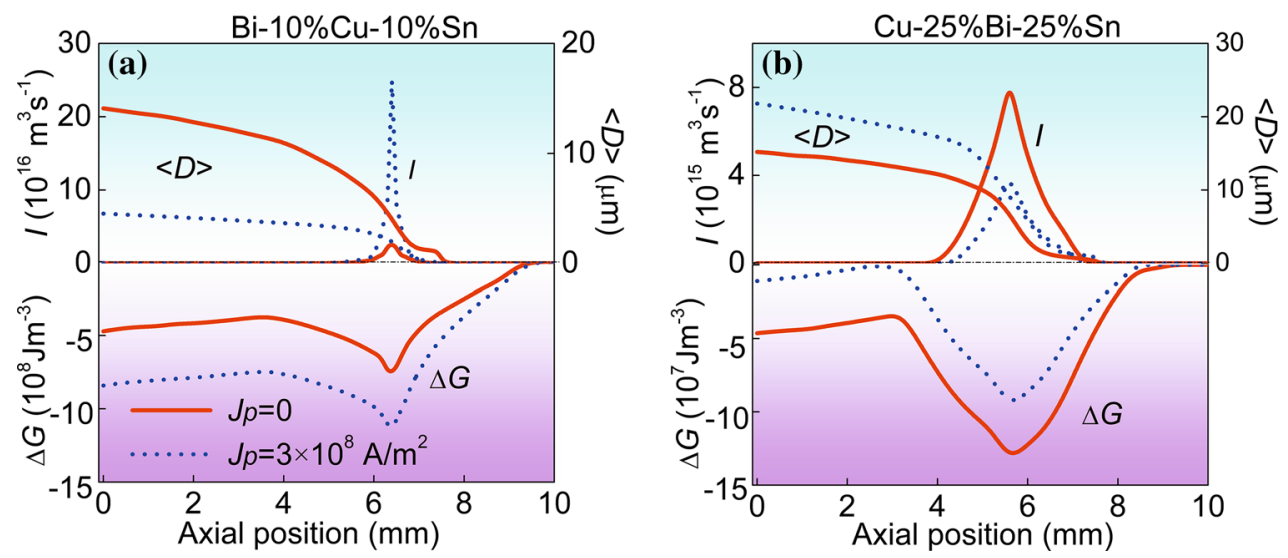

Fig. 13 Nucleation rate $(I)$, average diameter $(\langle D\rangle)$ of the MPDs and driving force for the nucleation $(\Delta G)$ of droplets in front of the solidification interface along the central axis for the a Bi-10 wt $\% \mathrm{Cu}-10 \mathrm{wt} \% \mathrm{Sn}, \mathbf{b} \mathrm{Cu}-25 \mathrm{wt} \% \mathrm{Bi}-25 \mathrm{wt} \% \mathrm{Sn}$ samples continuously solidified at the rate of $10 \mathrm{~mm} / \mathrm{s}$ under the effect of the ECPs. The frequency of the ECPs is $50 \mathrm{~Hz}$, and the duration of each ECP is $6 \mu \mathrm{s}$. $J_{\mathrm{p}}$ is the peak values of pulse current density [3]

shown in Fig. 14. They found that the orthogonal electricmagnetic fields may be used to compensate the specific gravity difference between the two liquids during the liquid-liquid decomposition of an immiscible alloy and imitate the microgravity condition. Samples with dispersed structure can be obtained when the parameters of the electric-magnetic fields were properly selected. Some others also investigated the solidification of immiscible alloys using this method later on. Ratke et al. [35] studied the influence of the orthogonal electric-magnetic fields on the solidification of $\mathrm{Cu}-\mathrm{Pb}$ immiscible alloys. The results indicate that the properly applied orthogonal electricmagnetic fields can efficiently reduce the sedimentation of $\mathrm{Pb}$-rich particles. Zhong et al. [36-39] investigated the effect of a high-strength static magnetic field coupled with alternating current on the solidification process of $\mathrm{Zn}-\mathrm{Bi}$ immiscible alloys. Their results demonstrated that $\mathrm{Zn}-\mathrm{Bi}$ alloys solidified in properly selected electric-magnetic fields may show a microstructure without macro-phase segregation, as shown in Fig. 15. 


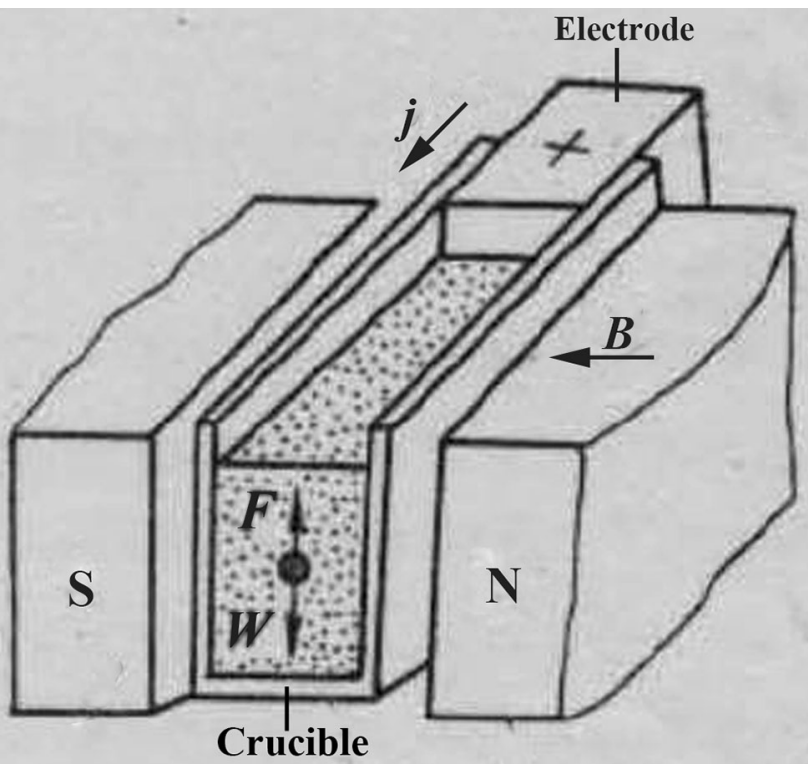

Fig. 14 Schematic diagram showing the solidification process of an immiscible alloy under the effect of an orthogonal electric-magnetic field. $W$ is the gravity. $F$ is the resultant force of the buoyancy and the electromagnetic force [34]

\section{Summary}

1. A magnetic field can significantly affect the microstructure evolution of immiscible alloys by suppressing the melt convective flow and inhibiting the collision and coagulations of the MPDs.

2. A DC mainly affects the solidification process of immiscible alloys by changing the spatial motions of the MPDs.

3. The ECPs mainly affect the microstructure formation of immiscible alloys by changing the nucleation behaviors of the MPDs.

4. Appropriate application of the magnetic field or electric current can control the solidification process and the microstructures of immiscible alloys, promote the formation of immiscible alloys with a desired composite microstructure, such as well-dispersed microstructure or core/shell microstructure, and thus have great prospects in industry for the manufacturing of immiscible alloys.
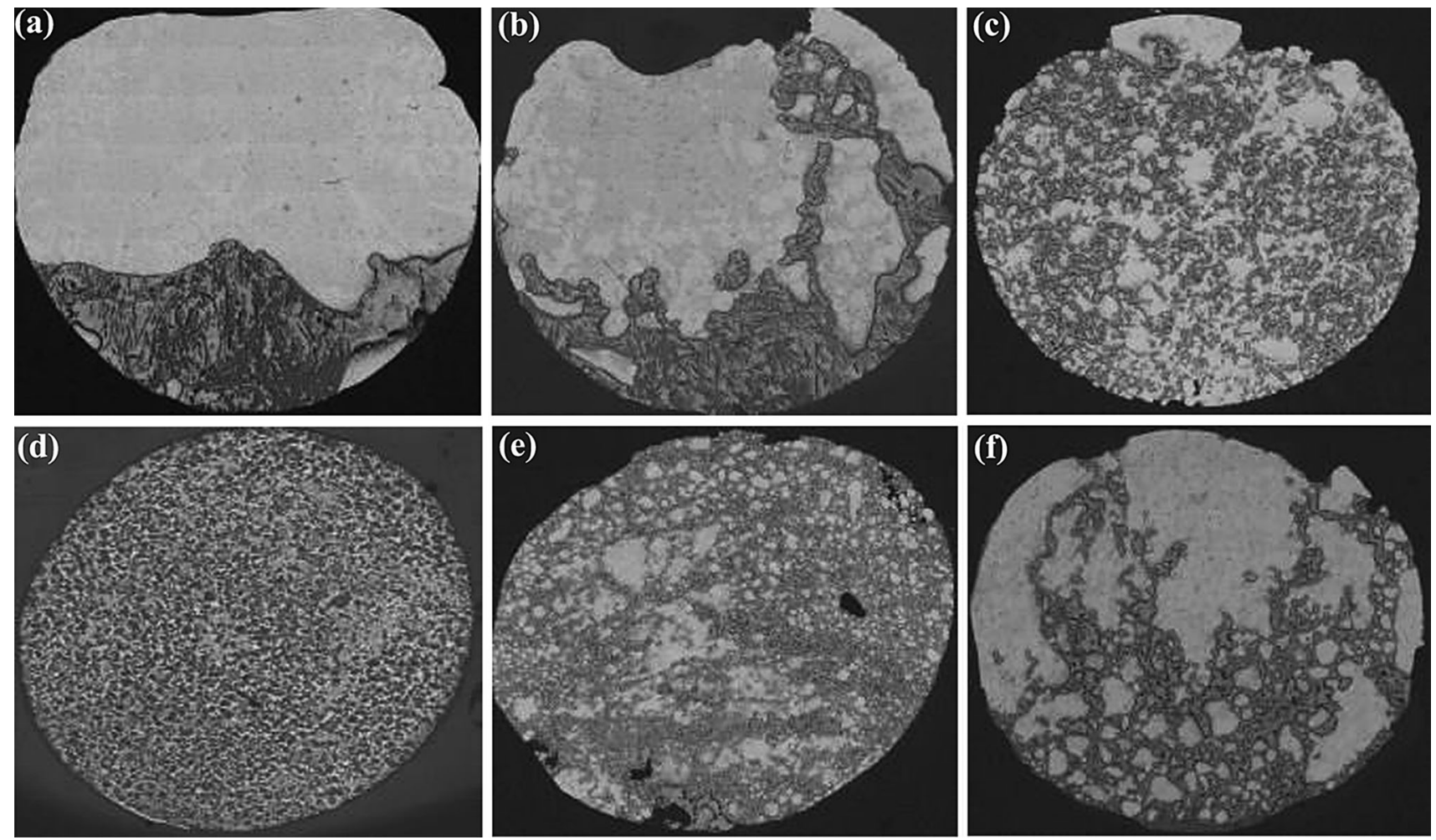

Fig. 15 Structures of Zn-30 wt $\%$ Bi alloys solidified under different electric magnetic body force magnitudes: a 0 N/cm ${ }^{3} ; \mathbf{b ~} 51$ N/cm 3 c 57 N/ $\mathrm{cm}^{3} ; \mathbf{d ~} 85 \mathrm{~N} / \mathrm{cm}^{3} ; \mathbf{e} 91 \mathrm{~N} / \mathrm{cm}^{3} ; \mathbf{f} 102 \mathrm{~N} / \mathrm{cm}^{3}$. The frequency of the electric magnetic body force and the cooling rate of the samples are $50 \mathrm{~Hz}$ and $25 \mathrm{~K} / \mathrm{min}$, respectively [36] 
Acknowledgements This work was financially supported by the National Natural Science Foundation of China (Grant Nos. 51771210, 51471173 and 51501207), the China's Manned Space Station Project (Mission No. TGJZ800-2-RW024) and the Natural Science Foundation of Liaoning Province (Grant No. 201501043).

\section{References}

[1] M.H. Wu, A. Ludwig, L. Ratke, Metall. Mater. Trans. A 34, 3009 (2003)

[2] L. Ratke, S. Diefenbach, Mater. Sci. Eng. R 15, 263 (1995)

[3] H.X. Jiang, J. He, J.Z. Zhao, Sci. Rep. 5, 12680 (2015)

[4] W.Q. Lu, S.G. Zhang, J.G. Li, Acta Metall. Sin. (Engl. Lett.) 29, 800 (2016)

[5] J.Z. Zhao, T. Ahmed, H.X. Jiang, J. He, Q. Sun, Acta Metall. Sin. (Engl. Lett.) 30, 1 (2017)

[6] Q. Sun, H.X. Jiang, J.Z. Zhao, J. He, Acta Mater. 129, 321 (2017)

[7] J.Z. Zhao, H.X. Jiang, Q. Sun, W. Li, J. He, Mater. China 36, 252 (2017)

[8] W.Q. Lu, S.Z. Zhang, W. Zhang, J.G. Li, J. Mater. Sci. Technol. 32, 1321 (2016)

[9] I. Kaban, M. Köhler, L. Ratke, W. Hoyer, N. Mattern, J. Eckert, A.L. Greer, Acta Mater. 59, 6880 (2011)

[10] C.P. Wang, X.J. Liu, I. Ohnuma, R. Kainuma, K. Ishida, Science 297, 990 (2002)

[11] P.L. Schaffer, R.H. Mathiesen, L. Arnberg, Acta Mater. 57, 2887 (2009)

[12] S.B. Luo, W.L. Wang, J. Chang, Z.C. Xia, B. Wei, Acta Mater. 69, 355 (2014)

[13] L. Zhao, J.Z. Zhao, Metall. Mater. Trans. A 43, 5019 (2012)

[14] S. Yang, W.J. Liu, J. Jia, J. Mater. Sci. 36, 5351 (2001)

[15] J. He, J.Z. Zhao, H.L. Li, X.F. Zhang, Q.X. Zhang, Metall. Mater. Trans. A 39, 1174 (2008)

[16] J. He, J.Z. Zhao, X.F. Wang, Q.X. Zhang, H.L. Li, G.Y. Chen, Acta Metall. Sin. 43, 567 (2007). (in Chinese)

[17] H.L. Li, J.Z. Zhao, Comput. Mater. Sci. 46, 1069 (2009)

[18] J.Z. Zhao, H.L. Li, Q.L. Wang, L. Zhao, J. He, Acta Metall. Sin. 45, 1344 (2009). (in Chinese)
[19] H. Yasuda, I. Ohnaka, S. Fujimoto, N. Takezawa, A. Tsuchiyama, T. Nakano, K. Uesugi, Scr. Mater. 54, 527 (2006)

[20] Y.K. Zhang, J. Gao, D. Nagamatsu, T. Fukud, H. Yasuda, M. Kolbe, J.C. He, Scr. Mater. 59, 1002 (2008)

[21] H. Yasuda, I. Ohnaka, O. Kawakami, K. Ueno, K. Kishio, ISIJ Int. 43, 942 (2003)

[22] L. Zhang, E.G. Wang, X.W. Zuo, J.C. He, Acta Metall. Sin. 46, 423 (2010). (in Chinese)

[23] T.X. Zheng, Y.B. Zhong, Z.S. Lei, W.L. Ren, Z.M. Ren, F. Debray, E. Beaugnon, Y. Fautrelle, J. Alloys Compd. 623, 36 (2015)

[24] H.X. Jiang, J.Z. Zhao, Chin. Phys. Lett. 29, 088104 (2012)

[25] H.X. Jiang, J.Z. Zhao, J. He, J. Mater. Sci. Technol. 30, 1027 (2014)

[26] H.X. Jiang, Dissertation, University of Chinese Academy of Sciences (2014). (in Chinese)

[27] J.Z. Zhao, H.X. Jiang, Chinese Patent, No. 201110242247, (2011). (in Chinese)

[28] J. Zhu, T.M. Wang, F. Cao, H.W. Fu, Y.N. Fu, H.L. Xie, T.Q. Xiao, J. Mater. Eng. Perform. 22, 1319 (2013)

[29] J. Zhu, T.M. Wang, F. Cao, Y.N. Fu, H.L. Xie, T.Q. Xiao, J. Phys. Conf. Ser. 463, 012036 (2013)

[30] H.X. Jiang, J.Z. Zhao, Chinese Patent, No. 201310553970 , (2013). (in Chinese)

[31] H.X. Jiang, J.Z. Zhao, C.P. Wang, X.J. Liu, Mater. Lett. 132, 66 (2014)

[32] T. Ahmed, H.X. Jiang, W. Li, J.Z. Zhao, Acta Metall. Sin. (Engl. Lett.) (2017). https://doi.org/10.1007/s40195-017-0685-1

[33] J.Z. Zhao, Y.Y. Chen, J.H. Zhang, J. Jia, Met. Sci. Technol. 9 , 77 (1990)

[34] J. Jia, J.Z. Zhao, J.H. Zhang, Y.Y. Chen, X.C. Chen, Chin. J. Mech. Eng. 4, 90 (1991)

[35] L. Ratke, D. Uffelmann, Mater. Sci. Forum 77, 69 (1991)

[36] Y.B. Zhong, J. Wang, T.X. Zheng, Y. Fautrelle, Z.M. Ren, Mater. Today Proc. 2S, S364 (2015)

[37] T.X. Zheng, Y.B. Zhong, Z.Q. Sun, J. Wang, Q.F. Wu, M.L. Feng, Z.M. Ren, Acta Phys. Sin. 61, 238501 (2012)

[38] J. Wang, Y.B. Zhong, W.L. Ren, Z.S. Lei, Z.M. Ren, K.D. Xu, Acta Phys. Sin. 58, 893 (2009)

[39] J. Wang, Y.B. Zhong, C. Wang, Z.Q. Wang, Z.M. Ren, K.D. Xu, Acta Phys. Sin. 60, 076101 (2011) 